\title{
Clear cell eccrine carcinoma with comedonecrosis in neck region: a rare case report and review of literature
}

This article was published in the following Dove Press journal:

Pathology and Laboratory Medicine International

14 September 2010

Number of times this article has been viewed

\author{
Alka H Hande \\ Archana M Sonone \\ Minal S Chaudhary \\ Department of Oral \\ and Maxillofacial Pathology, \\ Sharad Pawar Dental College, \\ Sawangi (Meghe), Wardha, India
}

Correspondence:Alka $\mathrm{H}$ Hande Department of Oral and Maxillofacial Pathology, Sharad Pawar Dental College, Sawangi (Meghe), Wardha, India Tel +9| 07| 52240068

$\mathrm{Fax}+9|07| 5224$ |7|।

Email alkahandel@yahoo.com

\begin{abstract}
Adnexal carcinomas of the skin are rare; they derive from structures such as sweat glands, sebaceous glands, and hair follicles. Adnexal tumors represent $1 \%-2 \%$ of skin cancers. Carcinomas of the eccrine sweat gland represent a rare group of tumors with potential for local destruction and metastasis. Clear cell changes are a prominent feature in a wide variety of squamous and adnexal carcinomas. Pure clear cell carcinomas of the skin are exceptionally rare. Eccrine clear cell carcinoma is most commonly seen in the scalp region. We represent a rare case report of clear cell eccrine carcinoma with comedonecrosis in the neck region which is an unusual location for this type of tumor.
\end{abstract}

Keywords: adnexal carcinomas, carcinomas of the eccrine sweat gland, clear cell eccrine carcinoma with comedonecrosis

\section{Introduction}

Malignant adnexal tumors are frequently located in the head and neck region but may appear on the fingers and toes, and on the trunk as well as the extremities. ${ }^{1}$ An incidence of approximately $0.005 \%$ has been cited for sweat gland carcinomas among all malignant epithelial neoplasms of the skin. ${ }^{2}$ The differential diagnosis between the most frequent skin tumors, such as basal cell carcinoma, squamous cell carcinoma (SCC), and the rare types, such as sweat gland carcinoma, is fundamental for the early diagnosis and prognosis of a patient. ${ }^{3}$

Carcinomas of the eccrine sweat gland represent a rare group of tumors with potential for local destruction and metastasis. Precise identification based on histology is of significant importance because therapy and prognosis vary according to microscopic appearance. Adnexal clear cell carcinoma with comedonecrosis appears to be a distinctive adnexal neoplasm that has to be distinguished from more indolent squamous cell and tricholemmal carcinomas.

Clear cell changes are a prominent feature in a wide variety of squamous and adnexal carcinomas. Pure clear cell carcinomas of the skin are exceptionally rare. ${ }^{4}$ Only a few cases have been reported in the literature under a variety of designations. The most commonly-used term is malignant nodular hidradenoma; however, similar cases also have been designated as: clear cell hidradenocarcinoma, malignant clear cell hidradenoma, malignant clear cell myoepithelioma, malignant clear cell acrospiroma, clear cell eccrine carcinoma, and malignant acrospiroma. ${ }^{5}$

We prefer to designate this eccrine tumor as clear cell eccrine carcinoma of the skin to implement a unifying theme highlighting the most striking histologic feature 
that distinguishes this tumor from other eccrine carcinomas and to avoid the confusing terminology in the literature.

Here we represent a rare case report of clear cell eccrine carcinoma with comedonecrosis in an unusual location, that is, on the neck.

\section{Case report}

A 71-year-old male patient reported to our outpatient clinic with the complaint of swelling in the right side of the neck which had started three years before. He had noticed a sudden increase in the size of the swelling four months earlier, which was associated with pain. Pain was gradual in onset, moderately radiating and nonreferred. There was no history of parasthesia but there had been a history of a change in his voice which had started four months earlier.

Examination revealed an extraoral swelling on the right side of the neck which was $1 \mathrm{~cm}$ anterior to the angle of the mandible. The swelling was approximately $5 \times 4 \mathrm{~cm}$. in size and oval in shape; the surface was lobulated and erythematous. On palpation it was firm in consistency and tender. Clinically no lymphadenopathy was elicited.

Fine needle aspiration cytology (FNAC) was done, but was nonconclusive. Histopathological diagnosis confirmed the clear cell eccrine carcinoma with comedonecrosis.

Reports on the therapy of eccrine carcinoma have stressed radical surgery as the treatment of choice and several authors have also advocated concurrent excision of regional lymph nodes. Though wide excision is the treatment of choice, the swelling was found to be adhered to the carotid vessel and hence could not be removed completely. Follow-up of the patient is ongoing.

\section{Discussion}

The concept that cutaneous carcinomas may show sweat gland differentiation was introduced in the mid-1800s. Unfortunately, the rarity of these lesions and the wide variation in their histologic appearance resulted in contradictions and confusion in the literature for many decades thereafter. ${ }^{2}$ Although the first commonly accepted case was reported by Cornil as early as $1865,{ }^{6}$ sweat gland carcinomas were still surrounded by mystery at the beginning of the 1950 s, because few cases had been described and those were not well documented. In 1943, reviewing the world literature up to 1939, Gates et al counted only 29 descriptions of sweat gland carcinomas, eight of which had been reported in the $1800 \mathrm{~s}^{7}{ }^{7}$ In 1951, Stout and Cooley opened the modern era of pathology of sweat gland carcinomas by giving a precise definition of such tumors. ${ }^{8}$ They reported 11 well-documented new cases, including six tumors that had metastasized and five that showed extensive local growth only. The authors also provided descriptions of particular histologic types of tumors, such as adenoid cystic carcinoma, mucinous carcinoma, and ductal carcinoma. The first classification of sweat gland carcinomas, however, dates back only to 1968, when Berg and McDivitt presented the largest series found in the literature and proposed a classification system paralleling that used for sweat gland adenomas. ${ }^{9}$ In sweat gland carcinomas, clear cell morphology is commonly observed, at least focally, in association with other more specific lines of differentiation that, by convention, determine the ultimate classification of the tumor. ${ }^{4}$ There are two ways in which eccrine gland carcinoma may arise:

1. It may arise de novo, that is directly from an eccrine gland through a malignant transformation. This is called primary eccrine carcinoma. Examples include eccrine adenocarcinoma (classic type), syringoid eccrine carcinoma, microcystic adnexal carcinoma, adenoid cystic carcinoma, mucinous eccrine carcinoma, aggressive digital papillary adenocarcinoma, and clear cell carcinoma.

2. It may develop from part of a preexisting eccrine appendage tumor of lesser maturity. For this diagnosis to be made there must be a recent change of an existing benign eccrine appendage tumor or histology must show both the benign eccrine appendage tumor and the malignant one together. For example, malignant eccrine poroma (porocarcinoma), malignant eccrine spiradenoma, malignant clear cell hidradenoma, and malignant chondroid syringoma. ${ }^{10,11}$

Malignant eccrine adnexal neoplasms characterized by a prominent clear-cell component are rare. Mehregan et al analyzed 35 cases collected over 20 years and found four distinct variants: eccrine porocarcinoma (18 cases), syringoid eccrine carcinoma (12 cases), mucinous eccrine carcinoma (3 cases), and clear cell carcinoma ( 2 cases). In his study, the commonest variants of eccrine carcinomas were eccrine tumors, ie, porocarcinoma. Primary eccrine carcinomas accounted for the rest. The clear cell variant accounted for $6 \%$ of his cases. In his study, eccrine carcinoma occurs from the fifth to the eighth decade of life. The carcinomas may be found on the extremities or the trunk. The lesions were locally destructive with a tendency to recur. Regional lymphatic and distant metastases occurred in $<10 \%$ and did not respond to radiation therapy. ${ }^{12}$

The largest series of clear cell eccrine carcinoma was reported by Wong et $\mathrm{al}^{5} \mathrm{He}$ studied nine cases collected over a period of 19 years. There were five males and four females, 
the mean age of presentation being 54 years. All presented with a solitary dermal or subcutaneous nodule, five on the head, two on the distal extremity, and one on the trunk. The size of the tumor ranged from $2-7 \mathrm{~cm}$. The lesion had been present for a period ranging from 3-12 years. The histological differentials include clear cell tumors of the skin such as SCC, basal cell carcinoma with adnexal differentiation, sebaceous carcinoma, balloon cell melanoma, and skin metastasis, especially renal cell carcinoma.

In 2001, Urso et $\mathrm{al}^{13}$ reported 60 cases of carcinomas of sweat gland collected over a period of 15 years, which were analyzed histologically and immunohistochemically. Among these 60 cases were porocarcinoma (41 cases), syringomatous carcinoma (3 cases), ductal carcinoma (8 cases), adenoid cystic carcinoma (5 cases), and mucinous carcinoma (3 cases). The major group of tumors in this series was the porocarcinomas (acrospirocarcinomas, clear cell hidradenocarcinomas). Porocarcinoma represents a broad spectrum of epidermal, juxtaepidermal, and dermal malignant tumors composed of atypical eosinophilic and clear cells arranged in solid masses and in sheets, which frequently show cystic excavations due to extensive necrosis.

Recently, Iskander et al reported on clinicopathologic analyses of 12 cases of adnexal clear cell carcinoma with comedonecrosis. Among these 12 cases, eight were in the head and neck region, and four on the extremities and the anal region. The histopathologic diagnosis revealed clear cell SCC (4 cases), sebaceous carcinoma (1 case), tricholemal carcinoma (1 case), clear cell SCC with comedonecrosis (1 case), clear cell SCC with suspected adnexal clear cell carcinoma with comedonecrosis (ACCCC) (2 cases), suspected ACCCC ( 2 cases), and SCC possible pilar tumor (1 case). ${ }^{4}$

Most patients in the literature were aged over 50 years, although in one case a tumor was present in a child aged 15 months and another was in a woman aged 29 years. There appears to be no sex predilection. In our report, the age of the male patient was 71 years. The majority of malignant tumors of the eccrine sweat gland occur on the skin of the head and on distal extremities. But in our case report the dermal nodule was present on the neck region which is a rare site for this carcinoma.

The typical clinical history is that of a dermal nodule that had been present for a long time and that showed a recent increase in size. The clinical features described in our case were similar to those described by other authors (Figure 1). Macroscopically the tumor mass represented as nonulcerated dermal nodules. On cut sections it appeared as homogenous, white- or tan-colored, circumscribed nodules,

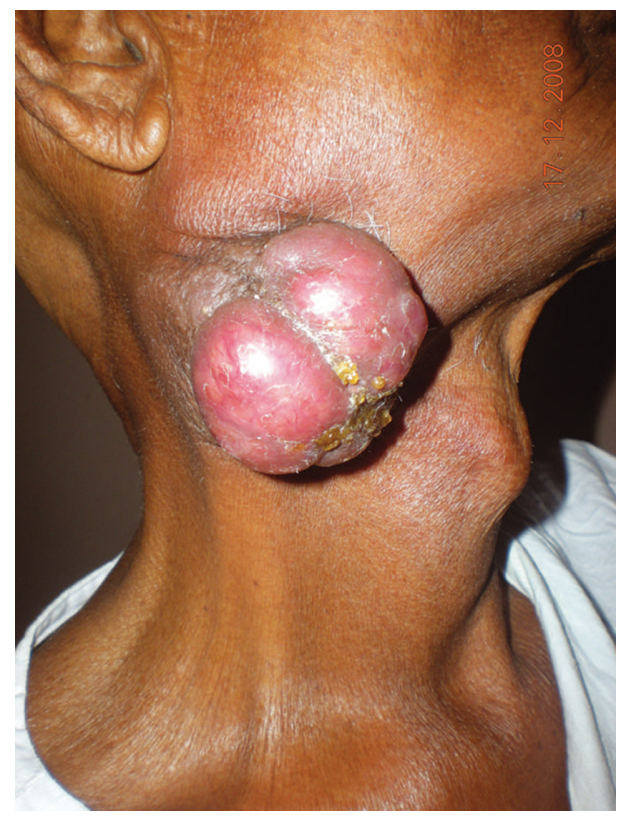

Figure I Dermal nodule present on right side of the neck region.

firm in consistency. In general, the tumor was expansile, oval in shape, and composed of discrete lobulated masses. The tumor was composed of solid, sheet like lobules, without any evidence of glandular or ductal lumen formation, and tumor lobules demonstrated an admixture of two cell types. On scanning magnification the dermis was occupied by the lobulated tumor mass with prominent central necrosis (comedo pattern) (Figure 2). At higher magnification large polyhedral-to-cuboidal cells with abundant clear cytoplasm, centrally placed nuclei, and distinct cell membranes were

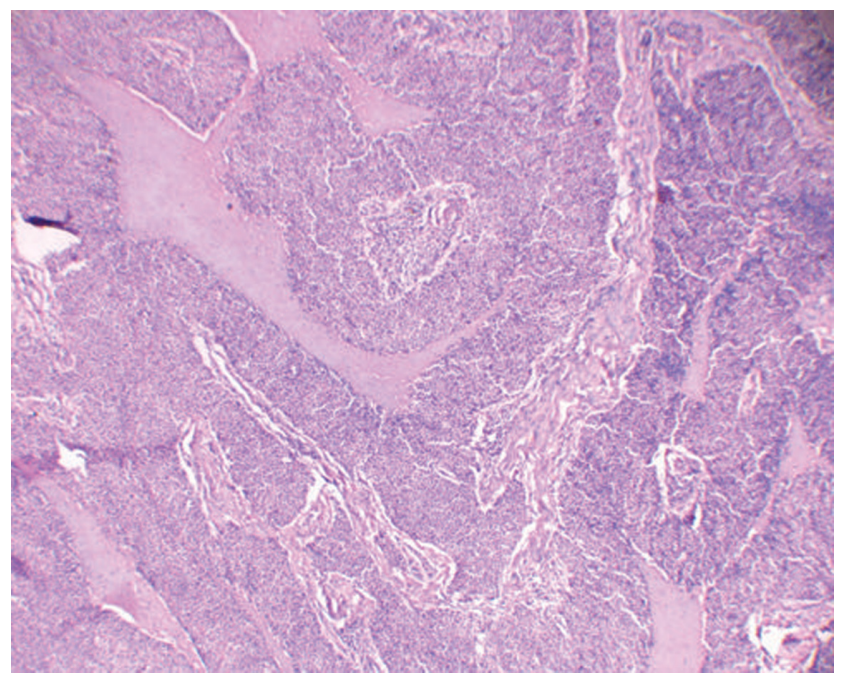

Figure 2 Dermis occupied by lobulated tumor mass with prominent central necrosis (comedo pattern) $(\mathrm{H}$ and $\mathrm{E}$, original magnification $\times 40)$. 


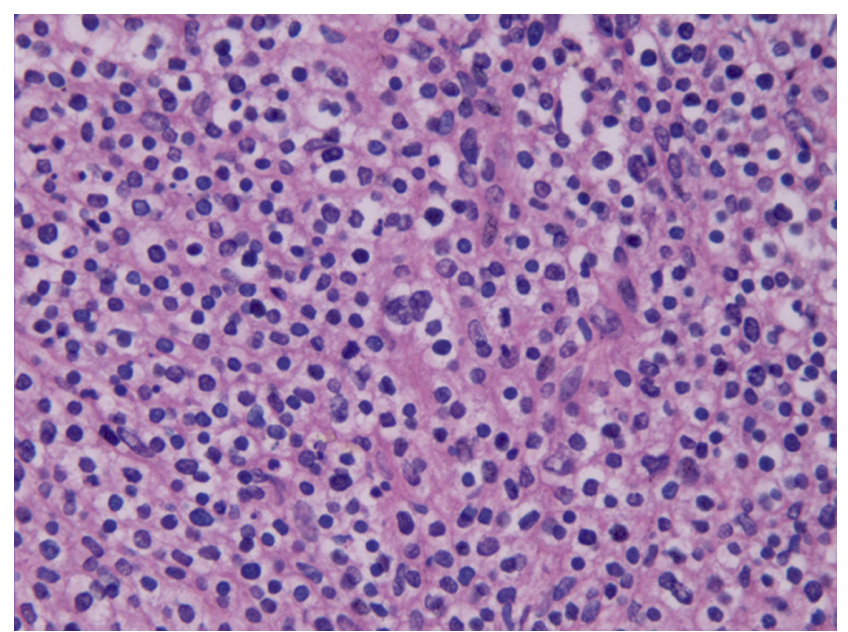

Figure 3 Polyhedral to cuboidal tumor cells exhibit clear cytoplasm, distinct cell membranes, and hyperchromatic nuclei. Mitotic figures also noted.

Notes: Hematoxylin and eosin, original magnification $\times 400$.

often the predominant cell type, and were present most commonly in groups and sheets located toward the central portion of the tumor (Figure 3). Other cell types included a spectrum of small polygonal to fusiform cells with eosinophilic cytoplasm. Individual tumor lobules showed squamous differentiation with such cells having atypical, round to oval, vesicular nuclei, small nucleoli, abundant cytoplasm, polygonal contours, and prominent intercellular bridges. Squamous pearls and single-cell keratinization was seen (Figure 4). Smaller tumor aggregates tended to be predominantly squamoid, whereas clear cell areas were most prominent in larger tumor nodules. The cytoplasmic clearing

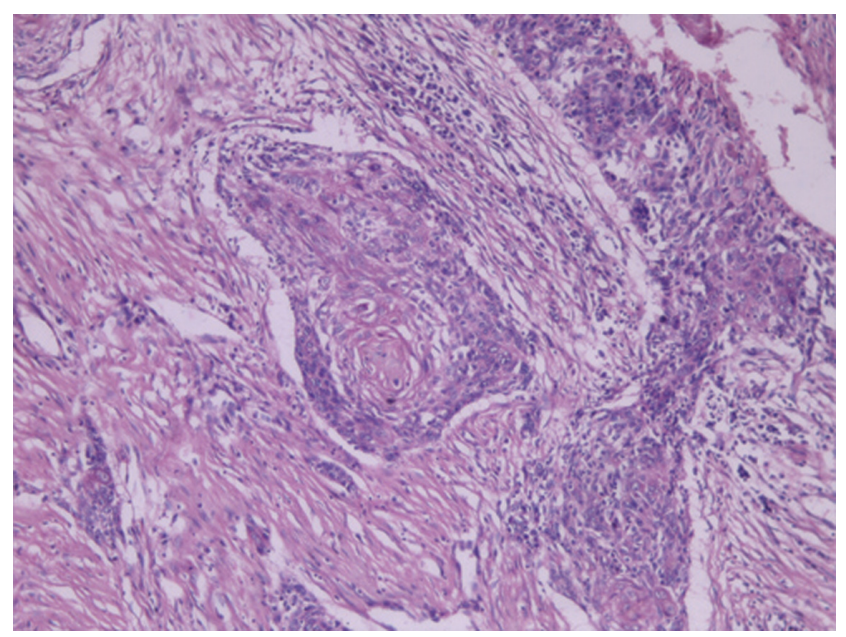

Figure 4 The tumor lobule was composed of polygonal to fusiform epithelial cells showing squamous differentiation.

Notes: Hematoxylin and eosin, original magnification $\times 100$.

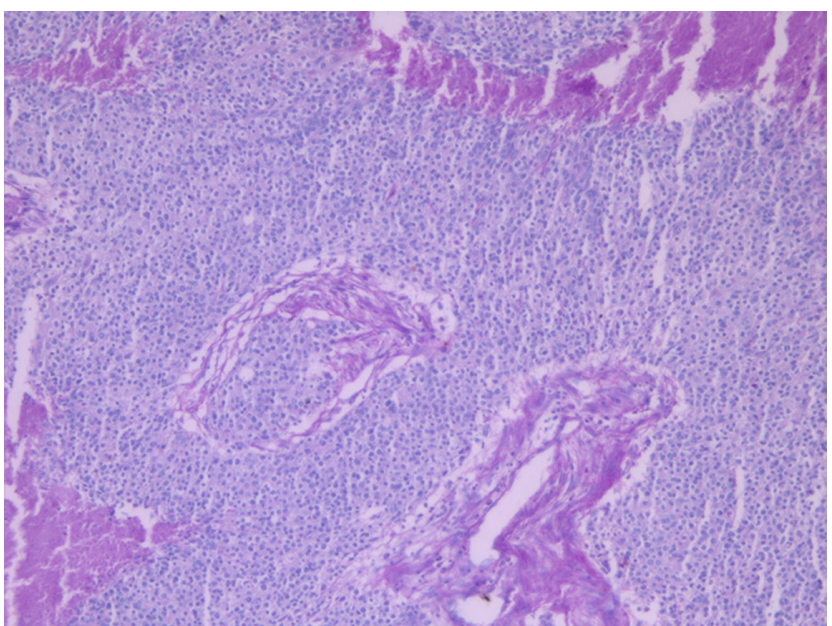

Figure 5 Clear cells showing positive reactivity with Periodic acid-Schiff stain. Notes: Periodic acid-Schiff, original magnification $\times 100$.

was due to accumulation of glycogen, which stained positive with Periodic acid-Schiff stain in a diastase-sensitive manner (Figure 5). The presence of tumor necrosis formed variably sized "comedones" in the center of large tumor aggregates. The surrounding stroma was densely sclerotic or hyalinized and often extended between the tumor masses to separate individual tumor lobules (Figure 6). A stromal-epithelial separation artifact was identified, especially in areas with a comedo component (Figure 7). The histopathological section does not show any benign component.

In the histopathological section the tissue comprised epidermis and dermis, and there was no salivary gland tissue.

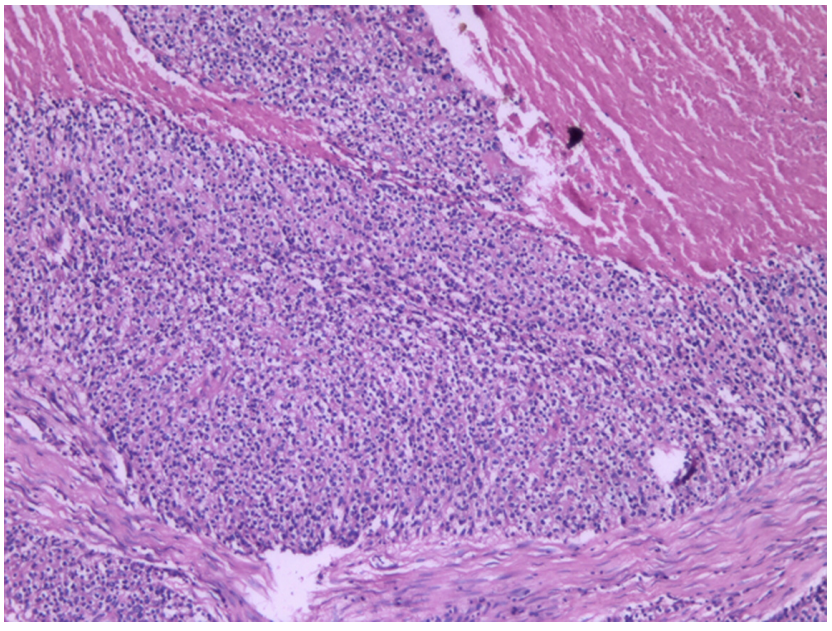

Figure 6 Densely sclerotic or hyalinized stroma and tumor necrosis forming 'comedons' extending between tumor lobules.

Notes: Hematoxylin and eosin, original magnification $\times 100$. 


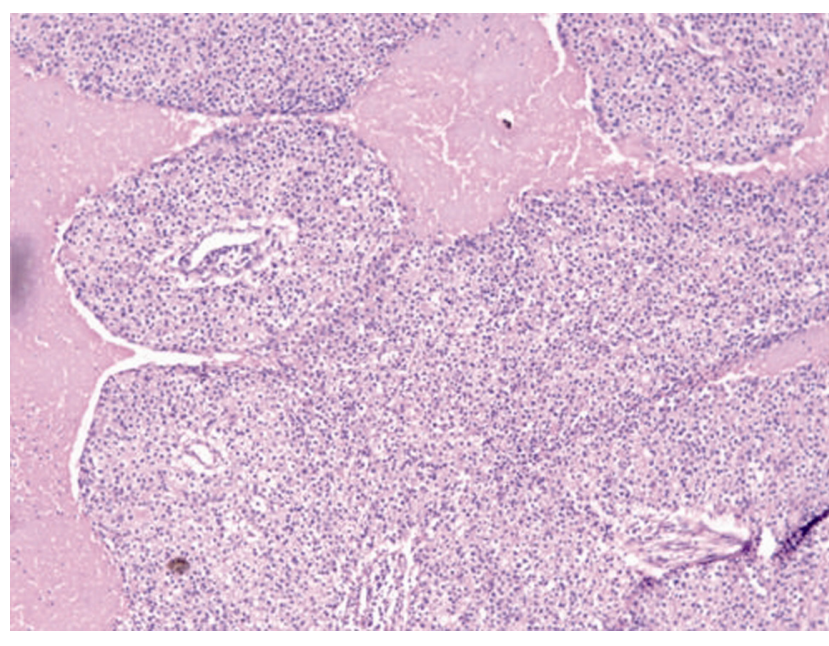

Figure $7 \mathrm{~A}$ stromal-epithelial separation artifact is noted. Notes: Hematoxylin and eosin, original magnification $\times 100$.

But the presence of adnexal tissue like sebaceous gland was noted, which inclines more towards an adnexal tumor, rather than a salivary gland tumor. Based on the clinical and histopathological characteristics, differential diagnosis of this case includes: mucoepidermoid carcinoma, (due to presence of squamous differentiation) carcinoma ex-pleomorphic adenoma, and metastasizing renal cell carcinoma. Origination of the lesion from salivary gland tissue was ruled out by the negative reactivity with mucicarmine staining (Figure 8 ) and the histopathological characteristics were typical of an adnexal tumor rather than a salivary gland tumor. The presence of squamoid foci with whorls and intralobular tubular formation excludes metastasizing carcinoma. Metastatic renal cell carcinoma usually shows marked vascularity and prominent

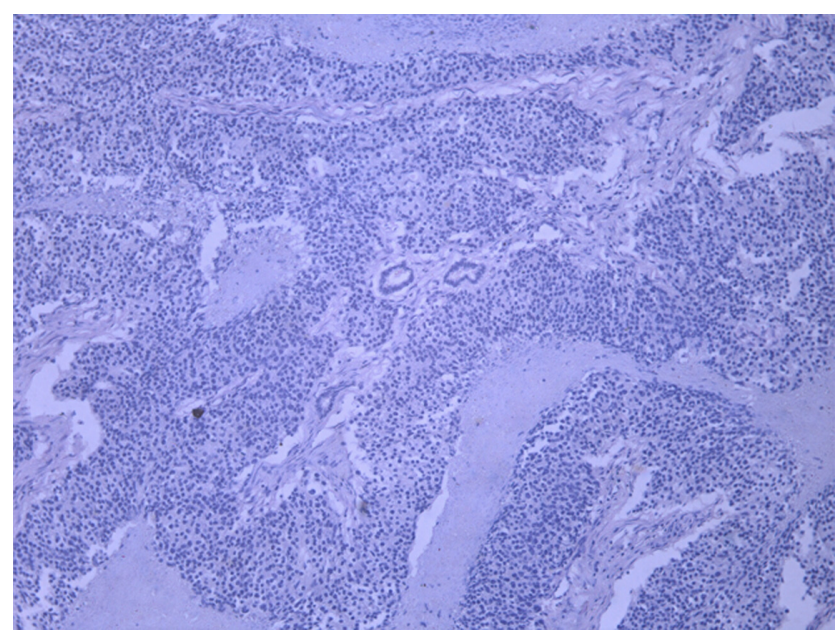

Figure 8 Negative reactivity of clear cells with mucicarmine. Notes: Mucicarmine stain, original magnification $\times 100$. hemorrhage throughout the tumor. These features were absent in our histopathological section. So the histopathological diagnosis is confirmed as a clear cell eccrine carcinoma with comedonecrosis.

The treatment of choice is complete surgical excision of the lesion with a margin of normal connective tissue at its periphery. When regional lymphatic metastatic nodes are present radical neck dissection is the treatment of election. Radiotherapy is ineffectual in controlling recurrent or metastatic tumor, according to results obtained in previous studies of these tumors. Chemotherapy has been utilized only sporadically for residual or metastatic tumors. ${ }^{2}$ Though wide excision is the treatment of choice, in our case the swelling was found to be adhered to the carotid vessel, and hence could not be removed completely. Follow-up of the patient is ongoing.

\section{Conclusion}

We report a case of eccrine clear cell carcinoma with comedonecrosis, a distinctive and potentially aggressive tumor, characterized by squamous differentiation, clear cell changes, and comedo-type necrosis.

Among the adnexal carcinomas, eccrine clear cell carcinoma is most commonly seen in the head and neck region, especially the scalp, but there is a wide anatomic distribution, including hair-bearing skin on the extremities and genital areas. ${ }^{4}$ In the studies by different authors the eccrine carcinoma was commonly seen in the head region but none was found on the neck. To the best of our knowledge this is the first case of eccrine clear cell carcinoma with comedonecrosis in the neck region.

\section{Disclosure}

The authors report no conflicts of interest in this work.

\section{References}

1. Güerrissi JO, Quiroga JP. Adnexal carcinomas of the head and neck. Indian J Plast Surg. 2008;41(2):229-234.

2. Wick MR, Goellner JR, Wolfe JT, Daniel WP. Adnexal carcinoma of skin I. eccrine carcinoma. Cancer. 1985;56(5):1147-1162.

3. Leonhardt FD, Zanoni A, Ponce F, et al. Eccrine sweat gland carcinoma. Rev Bras Otorrinolaringol. 2007;73(2):286.

4. Iskander $\mathrm{CH}, \mathrm{Zembowicz} \mathrm{A}$. Adnexal clear cell carcinoma with comedonecrosis: clinicopathologic analysis of 12 cases. Arch Pathol Lab Med. 2007;131(11):1655-1664.

5. Wong TY, Suster S, Nogita T, Duncan LM, Dickersin RG, Mihm MC. Clear cell eccrine carcinomas of the skin. A clinicopathologic study of nine patients. Cancer. 1994;73(6):1631-1643.

6. Cornil V. Metastasizing carcinoma of sweat glands. Br J Surg. 1955;43: 80-84.

7. Gates O, Warren S, Warvi WN. Tumors of sweat glands. Am J Pathol. 1943;19:591-631. 
8. Stout AP, Cooley SGE. Carcinoma of sweat glands. Cancer. 1951;4: $521-536$.

9. Berg JW, McDivitt RW. Pathology of sweat gland carcinomas. Pathol Аппи. 1968;3:123-144.

10. Kwok C. Clear Cell Variant of Eccrine Carcinoma and Review of the Literature. Bulletin for medical practitioners. Singapore: National Skin Centre; 1995.

11. Elder D, Elenitsas R, Ragsdale BD. Tumors of the epidermal appendages. In: Elder D, Elenitsas R, Jaworsky C, Johnson B Jr, editors. Lever's Histopathology of the Skin. 8th ed. Philadelphia, PA: Lippincott-Raven; 1997:759-761.
12. Mehregan AH, Hashimoto K, Rahbari H. Eccrine adenocarcinoma. A clinicopathologic study of 35 cases. Arch Dermatol. 1983;119: 104-114.

13. Urso C, Bondi R, Paglierani M, Salvadori A, Anichini C, Gannini A. Carcinomas of sweat glands. Report of 60 cases. Arch Pathol Lab Med. 2001;125(4):498-505.

\section{Publish your work in this journal}

Pathology and Laboratory Medicine International is a peer-reviewed, open access journal focusing on innovative basic research and translational research related to pathology or human disease. The journal includes original research, updates, case reports, reviews and commentaries on current controversies. The Academic Sponsor of this journal is the Chinese American Pathology Association (CAPA). The manuscript management system is completely online and includes a very quick and fair peer-review system. Visit http://www.dovepress.com/testimonials.php to read real quotes from published authors.

Submit your manuscript here: http://www.dovepress.com/pathology-and-laboratory-medicine-international-journal 